\title{
A Green Preconcentration Method for Determination of Cobalt and Lead in Fresh Surface and Waste Water Samples Prior to Flame Atomic Absorption Spectrometry
}

\author{
Naeemullah, Tasneem Gul Kazi, Faheem Shah, Hassan Imran Afridi, Sumaira Khan, \\ Sadaf Sadia Arian, and Kapil Dev Brahman
}

National Centre of Excellence in Analytical Chemistry, University of Sindh, Jamshoro 76080, Pakistan

Correspondence should be addressed to Naeemullah, naeemullah433@yahoo.com

Received 4 July 2012; Accepted 5 October 2012

Academic Editor: Jolanta Kumirska

Copyright () 2012 Naeemullah et al. This is an open access article distributed under the Creative Commons Attribution License, which permits unrestricted use, distribution, and reproduction in any medium, provided the original work is properly cited.

\begin{abstract}
Cloud point extraction (CPE) has been used for the preconcentration and simultaneous determination of cobalt (Co) and lead $(\mathrm{Pb})$ in fresh and wastewater samples. The extraction of analytes from aqueous samples was performed in the presence of 8hydroxyquinoline (oxine) as a chelating agent and Triton X-114 as a nonionic surfactant. Experiments were conducted to assess the effect of different chemical variables such as $\mathrm{pH}$, amounts of reagents (oxine and Triton X-114), temperature, incubation time, and sample volume. After phase separation, based on the cloud point, the surfactant-rich phase was diluted with acidic ethanol prior to its analysis by the flame atomic absorption spectrometry (FAAS). The enhancement factors 70 and 50 with detection limits of $0.26 \mu \mathrm{g} \mathrm{L}^{-1}$ and $0.44 \mu \mathrm{g} \mathrm{L}^{-1}$ were obtained for $\mathrm{Co}$ and $\mathrm{Pb}$, respectively. In order to validate the developed method, a certified reference material (SRM 1643e) was analyzed and the determined values obtained were in a good agreement with the certified values. The proposed method was applied successfully to the determination of $\mathrm{Co}$ and $\mathrm{Pb}$ in a fresh surface and waste water sample.
\end{abstract}

\section{Introduction}

Release of large quantities of metals into the environment (especially in natural water) is responsible for a number of environmental problems [1]. Metals are major pollutants in marine, ground, industrial, and even treated waste waters [2]. Industrial wastes are the major source of various kinds of toxic metals which have nonbiodegradability and persistence properties resulted in a number of public health problems [3]. Metals of interest, cobalt $(\mathrm{Co})$ and lead $(\mathrm{Pb})$, were chosen based on their industrial applications and potential pollution impact on the environment [4].

$\mathrm{Pb}$ is a toxic metal and widely distributed in the environment. It is an accumulative toxic metal, which is responsible for a number of health problems [5].

$\mathrm{Pb}$ reaches humans from natural as well as anthropogenic sources, for example, drinking water, soils, industrial emissions, car exhaust, and contaminated food and beverages. Therefore, highly sensitive and selective methods have needed to be developed to determine the trace level of $\mathrm{Pb}$ in water samples. The maximum contaminant levels of $\mathrm{Pb}$ in drinking water allowed by environmental protection agency (EPA) is $15.0 \mu \mathrm{g} \mathrm{L}^{-1}$, while the world health organization (WHO) for drinking water quality containing the guideline value of $10 \mu \mathrm{g} \mathrm{L}^{-1}[6,7]$.

Co is known to be an essential micronutrient for metabolic processes in both plants and animals [8]. It is mainly found in rocks, soil, water, plants, and animals. The determination of trace level of Co in natural waters is very important because Co is important for living species and it is part of vitamin B12 [9]. Exposures to a high level of Co lead to serious public health problems and are responsible for several diseases in human such as in lung, heart, and skin [10].

Flame atomic absorption spectrometry (FAAS) is a widely used technique for quantification of metal species. The determination of metals in water samples is usually associated with a step of preconcentration of the analyte 
before detection [11]. The determination of trace levels of $\mathrm{Pb}$ and $\mathrm{Co}$ in water samples is particularly difficult because of the usually low concentration; on the bases of these facts a great effort is needed to develop highly sensitive and selective methods to simultaneously determine trace level of these metals in water samples $[12,13]$.

A variety of procedures for preconcentration of metals, such as solid phase extraction (SPE) [14], liquid-liquid extraction (LLE) [15], and coprecipitation and cloud point extraction (CPE) [16] have been developed. Among them, CPE is one of the most reliable and sophisticated separation methods for the enrichment of trace metals from different types of samples. While other methods such as LLE are usually time consuming and labor intensive and require relatively large volumes of solvents, which are not only responsible for public health problems but also a major cause of environmental pollution [17-22]. It was reported in literature that $\mathrm{Pb}$ and $\mathrm{Co}$ had been preconcentrated by CPE method after the formation of sparingly watersoluble complexes with different chelating agents such as ammonium pyrrolidine dithiocarbamate (APDC) $[23,24] 1$ (2-thiazolylazo)-2-naphthol (TAN) [25], 1-(2-pyridylazo)2-naphthol (PAN) [26, 27], and diethyldithiocarbamate (DDTC) [28-30].

In the present work, we introduce a simple, sensitive, selective, and low-cost procedure for simultaneous preconcentration of $\mathrm{Co}$ and $\mathrm{Pb}$ after the formation of complex with oxine, using Triton X-114 as surfactant and later analysis by flame atomic absorption spectrometry. Several experimental variables affecting the sensitivity and stability of separation/preconcentration method were investigated in detail. The proposed method was applied for the determination of trace amount of both metals in fresh surface and waste water samples.

\section{Experimental}

2.1. Chemical Reagents and Glassware. Ultrapure water, obtained from ELGA lab water system (Bucks, UK), was used throughout the work. The nonionic surfactant Triton X-114 was obtained from Sigma (St. Louis, MO, USA) and was used without further purification. Stock standard solution of $\mathrm{Pb}$ and $\mathrm{Co}$ at a concentration of $1000 \mu \mathrm{g} \mathrm{L}^{-1}$ was obtained from the Fluka Kamica (Bush, Switzerland). Working standard solutions were obtained by appropriate dilution of the stock standard solutions before analysis. Concentrated nitric acid and hydrochloric acid were analytical reagent grade from Merck (Darmstadt, Germany) and were checked for possible trace $\mathrm{Pb}$ and Co contamination by preparing blanks for each procedure. The 8-hydroxyquinoline (oxine) was obtained from Merck, prepared by dissolving appropriate amount of reagent in $10 \mathrm{~mL}$ ethanol and diluting to $100 \mathrm{~mL}$ with $0.01 \mathrm{M}$ acetic acid, and were kept in a refrigerator $4{ }^{\circ} \mathrm{C}$ for one week. The $0.1 \mathrm{M}$ acetate and phosphate buffer were used to control the $\mathrm{pH}$ of the solutions. The $\mathrm{pH}$ of the samples was adjusted to the desired $\mathrm{pH}$ by the addition of $0.1 \mathrm{~mol} \mathrm{~L}^{-1} \mathrm{HCl} / \mathrm{NaOH}$ solution in the buffers. For the accuracy of methodology, a certified reference material of water SRM-1643e, National
Institute of Standards and Technology (NIST, Gaithersburg, MD, USA) was used. The glass and plastic wares were soaked in $10 \%$ nitric acid overnight and rinsed many times with deionized water prior to use to avoid contamination.

2.2. Instrumentation. A centrifuge of WIROWKA Laboratoryjna type WE-1, nr-6933 (speed range 0-6000 rpm, timer 0$60 \mathrm{~min}, 220 / 50 \mathrm{~Hz}$, Mechanika Phecyzyjna, Poland) was used for centrifugation. The $\mathrm{pH}$ was measured by $\mathrm{pH}$ meter (720pH meter, Metrohm). Global positioning system (iFinder GPS, Lowrance, Mexico) was used for sampling locations.

A Perkin Elmer Model 700 (Norwalk, CT, USA) atomic absorption spectrometer, equipped with hollow cathode lamps and an air-acetylene burner. The instrumental parameters were as follows: wavelength 240.7 and $283.3 \mathrm{~nm}$ and slit widths: 0.2 and $0.7 \mathrm{~nm}$ for Co and Pb. Deuterium lamp background correction was also used.

2.3. Sample Collection and Preparation Procedure. The fresh surface water samples (canals) and waste water were collected on alternate month in 2011 from twenty (20) different sampling sites of Jamshoro, Sindh (southern part of Pakistan) with the help of the global positioning system (GPS). The understudy district positioned between $25^{\circ} 19-26^{\circ} 42 \mathrm{~N}$ and $67^{\circ} 12-68^{\circ} 02 \mathrm{E}$. The sampling network was designed to cover a wide range of the whole district. The industrial waste water samples of understudy areas were also collected. All water samples were filtered through a 0.45 micropore size membrane filter to remove suspended particulate matter and were stored at $4^{\circ} \mathrm{C}$.

2.4. General Procedure for CPE. For $\mathrm{Co}$ and $\mathrm{Pb}$ determination, aliquot of $25 \mathrm{~mL}$ of the standard or sample solution containing both analytes $(20-100 \mu \mathrm{g} / \mathrm{L})$, oxine $5 \times$ $10^{-3} \mathrm{~mol} \mathrm{~L}^{-1}$ and Triton X-114 0.5\% (v/v), were added. To reach the cloud point temperature, the system was allowed to stand for about $30 \mathrm{~min}$ into an ultrasonic bath at $50^{\circ} \mathrm{C}$ for $10 \mathrm{~min}$. Separation of the two phases was achieved by centrifuging for $10 \mathrm{~min}$ at $3500 \mathrm{rpm}$. The contents of tubes were cooled down in an ice bath for $10 \mathrm{~min}$. The supernatant was then decanted by inverting the tube. The surfactantrich phase was treated with $200 \mu \mathrm{L}$ of $0.1 \mathrm{~mol} \mathrm{~L}^{-1} \mathrm{HNO}_{3}$ in ethanol $(1: 1, \mathrm{v} / \mathrm{v})$ in order to reduce its viscosity and facilitate sample handling. The final solution was introduced into the flame by conventional aspiration. Blank solution was submitted to the same procedure and measured in parallel to the standards and real samples.

\section{Result and Discussion}

3.1. Optimization of CPE. The preconcentration of $\mathrm{Pb}$ and Co was based on the formation of a neutral, hydrophobic complex with oxine, which is subsequently trapped in the micellar phase of a nonionic surfactant (Triton X-114). Utilizing the thermally induced phase extraction separation process known as CPE, the analyte is highly preconcentrated and free of interferences in a very small micellar phase. Several parameters play a significant role in the performance of 
the surfactant system that is used and its ability to aggregate, thus entrapping the analyte species. The $\mathrm{pH}$, complexing reagent and surfactant concentration, temperature, and time were studied for optimum analytical signals.

3.2. Effect of $p H$. The effect of $\mathrm{pH}$ on the $\mathrm{CPE}$ of $\mathrm{Co}$ and $\mathrm{Pb}$ was investigated because this parameter plays an important role in metal-chelate formation. The effect of $\mathrm{pH}$ upon the extraction of $\mathrm{Co}$ and $\mathrm{Pb}$ ions from the six replicate standard solutions $20.0 \mu \mathrm{g} \mathrm{L}^{-1}$ was studied within the $\mathrm{pH}$ range of 310 , while each operational desired $\mathrm{pH}$ value was obtained by the addition of $0.1 \mathrm{~mol} \mathrm{~L}^{-1}$ of $\mathrm{HNO}_{3} / \mathrm{NaOH}$ in the presence of acetate/borate buffer. The maximum extraction efficiency of understudy metals was obtained at $\mathrm{pH}$ range of 6.5-7.5 as shown in Figure 1, for subsequent work pH 7.0 was chosen as the optimum for subsequent work.

3.3. Effect of Triton $X-114$ Concentration. Separation of metal ions by a cloud point method involves the prior formation of a complex with sufficient hydrophobicity to be extracted in a small volume of surfactant-rich phase. The temperature corresponding to cloud point is correlated with the hydrophilic property of surfactants. The nonionic surfactant Triton X-114 was chosen as surfactant due to its low cloud point temperature and high density of the surfactant-rich phase, which facilitates phase separation by centrifugation. The effect of Triton X-114 concentrations on the extraction efficiencies of $\mathrm{Co}$ and $\mathrm{Pb}$ were examined at the range of 0.1 to $1.0 \%(\mathrm{v} / \mathrm{v})$. Figure 2 shows that quantitative extraction was observed when surfactant concentration was $>0.5 \%$ $(\mathrm{v} / \mathrm{v})$. At lower concentrations, the extraction efficiency of complexes was low probably because of the inadequacy of the assemblies to entrap the hydrophobic complex quantitatively. A Triton X-114 concentration of $0.5 \%(\mathrm{v} / \mathrm{v})$ was selected for subsequent studies.

3.4. Effect of Oxine Concentration. The oxine is a relatively very stable and selective hydrophobic complexing reagent which reacts with both selected cations. Replicate $10 \mathrm{~mL}$ of standard, SRM, and real sample solution in $0.5 \%(\mathrm{w} / \mathrm{v})$ Triton $\mathrm{X}-114$ at a buffer of $\mathrm{pH} 7.0$ and complexed with oxine solutions in the range of $1.0-10.0 \times 10^{-3} \mathrm{~mol} \mathrm{~L}^{-1}$. The results revealed in Figure 3 that extraction efficiency of both metals increases up to $5 \times 10^{-3} \mathrm{~mol} \mathrm{~L}^{-1}$. This value was, therefore, selected as the optimal chelating agent concentration. The concentrations above this value have no significant effect on the efficiency of CPE.

3.5. Effects of Sample Volume on Preconcentration Factor. The preconcentration factor (PCF) is defined as the concentration ratio of the analyte in the final diluted surfactant-rich extract ready for its determination and in the initial solution. Among the other factors, this depends on the phase relationship, on the distribution constant of the analyte between the phases, and on sample volume. The sample volume is one of the most important parameters in the development of the preconcentration method, since it determines the sensitivity and enhancement of the technique. The phase

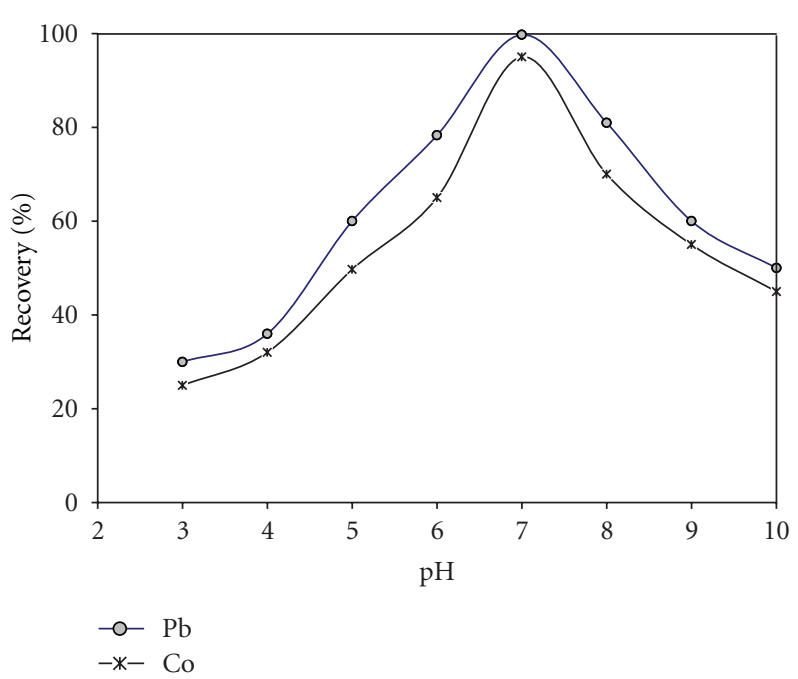

Figure 1: Effect of $\mathrm{pH}$ on the percentage of recovery: $20 \mu \mathrm{g} \mathrm{L}^{-1}$ of $\mathrm{Pb}$ and $\mathrm{Co}, 5.0 \times 10^{-3} \mathrm{~mol} \mathrm{~L}^{-1}$ oxine, $0.5 \%(\mathrm{v} / \mathrm{v})$ Triton X-114, temperature $50^{\circ} \mathrm{C}$, and centrifugation time $10 \mathrm{~min}(3500 \mathrm{rpm})$.

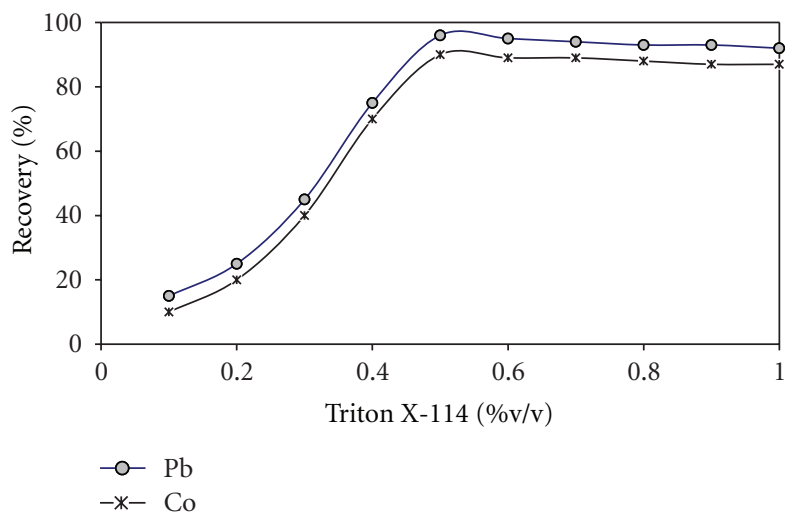

FIGURE 2: Effect of Triton X-114 on the percentage of recovery: $20 \mu \mathrm{g} \mathrm{L}^{-1}$ of $\mathrm{Pb}$ and $\mathrm{Co}, 5.0 \times 10^{-3} \mathrm{~mol} \mathrm{~L}^{-1}$ oxine, $\mathrm{pH} 7.0$, temperature $50^{\circ} \mathrm{C}$, and centrifugation time $10 \mathrm{~min}(3500 \mathrm{rpm})$.

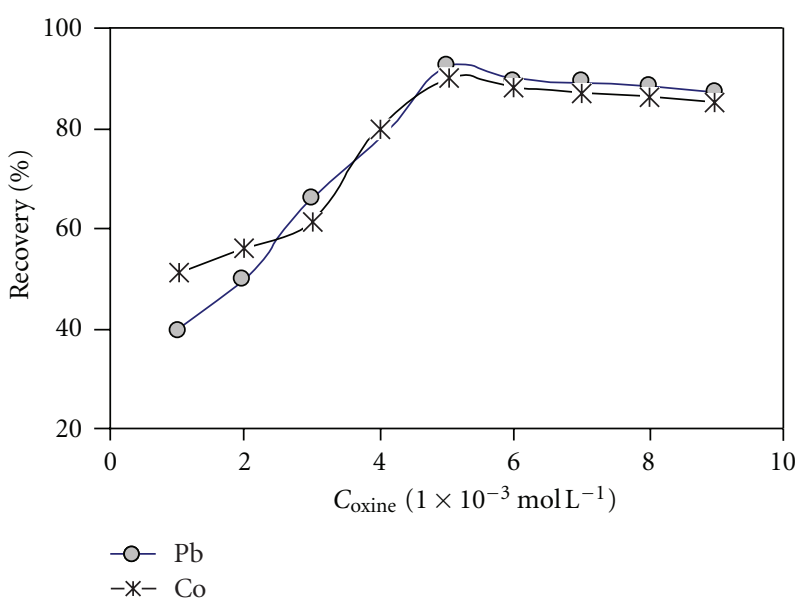

Figure 3: Effect of oxine concentration on the percentage of recovery: $20 \mu \mathrm{g} \mathrm{L}^{-1}$ of $\mathrm{Pb}$ and Co, $0.5 \%$ (v/v) Triton X-114, $\mathrm{pH} 7.0$, temperature $50^{\circ} \mathrm{C}$, and centrifugation time $10 \mathrm{~min}(3500 \mathrm{rpm})$. 
TABLE 1: Influences of some foreign ions on the recoveries of cobalt and lead $\left(20 \mu \mathrm{g} \mathrm{L}^{-1}\right)$ determination by applied CPE method.

\begin{tabular}{lccc}
\hline Ion & Concentration $\left(\mu \mathrm{g} \mathrm{L}^{-1}\right)$ & Pb recovery $(\%)$ & Co recovery $(\%)$ \\
\hline $\mathrm{Na}^{+}$ & 20000 & $97 \pm 2.14$ & $98 \pm 2.22$ \\
$\mathrm{~K}^{+}$ & 5000 & $98 \pm 2.21$ & $99 \pm 3.02$ \\
$\mathrm{Ca}^{2+}$ & 5000 & $98 \pm 2.12$ & $97 \pm 1.12$ \\
$\mathrm{Mg}^{2+}$ & 5000 & $97 \pm 1.04$ & $98 \pm 3.08$ \\
$\mathrm{Cl}^{-}$ & 30000 & $99 \pm 2.05$ & $98 \pm 3.04$ \\
$\mathrm{~F}^{-}$ & 1000 & $96 \pm 3.01$ & $97 \pm 1.12$ \\
$\mathrm{NO}^{3-}$ & 3000 & $97 \pm 1.04$ & $98 \pm 3.06$ \\
$\mathrm{HCO}_{3}^{-}$ & 1000 & $98 \pm 3.12$ & $97 \pm 2.04$ \\
$\mathrm{Al}^{3+}$ & 500 & $97 \pm 2.21$ & $99 \pm 3.05$ \\
$\mathrm{Fe}^{3+}$ & 50 & $96 \pm 2.23$ & $97 \pm 3.02$ \\
$\mathrm{Zn}^{2+}$ & 100 & $97 \pm 3.05$ & $96 \pm 2.32$ \\
$\mathrm{Cr}^{3+}$ & 100 & $96 \pm 2.08$ & $98 \pm 2.25$ \\
$\mathrm{Cd}^{2+}$ & 100 & $97 \pm 3.12$ & $98 \pm 3.22$ \\
$\mathrm{Ni}^{2+}$ & 100 & $96 \pm 2.23$ & $97 \pm 3.01$ \\
\hline
\end{tabular}

TABLE 2: Analytical characteristics of the proposed method.

\begin{tabular}{lcccccc}
\hline Element condition & Concentration range $\left(\mu \mathrm{g} \mathrm{L}^{-1}\right)$ & Slope & Intercept & $R^{2}$ & R.S.D. $(n=5)^{\mathrm{a}}$ & $\left.\mathrm{LOD}^{\mathrm{b}}(\mu \mathrm{g} \mathrm{L})^{-1}\right)$ \\
\hline Co without preconcentration & $250-5000$ & $3.97 \times 10^{-3}$ & -0.013 & 0.9871 & $1.45(500)$ & 32.0 \\
Co with preconcentration & $20.0-100$ & 0.279 & +0.008 & 0.9997 & $2.22(20)$ & 0.26 \\
Pb without preconcentration & $250-5000$ & $5.03 \times 10^{-3}$ & -0.034 & 0.9972 & $0.88(600)$ & 46.0 \\
Pb with preconcentration & $20.0-100$ & 0.256 & -0.012 & 0.9989 & $1.88(30)$ & 0.44 \\
\hline
\end{tabular}

avalues in parentheses are the $\mathrm{Co}$ and $\mathrm{Pb}$ concentrations $\left(\mu \mathrm{g} \mathrm{L}^{-1}\right)$ for which the RSD was obtained.

${ }^{b}$ Limit of detection, calculated as three times the standard deviation of the blank signal.

TABLE 3: Determination of cobalt and lead in certified reference material and water samples.

(a)

\begin{tabular}{|c|c|c|c|c|c|c|c|}
\hline \multirow{2}{*}{\multicolumn{2}{|c|}{ Certified reference material }} & \multicolumn{2}{|c|}{ Certified values $\left(\mu \mathrm{g} \mathrm{L}^{-1}\right)$} & \multicolumn{2}{|c|}{ Measured values $\left(\mu \mathrm{g} \mathrm{L}^{-1}\right)$} & \multicolumn{2}{|c|}{ Percentage of recovery (RSD \%) } \\
\hline & & Co & $\mathrm{Pb}$ & Co & $\mathrm{Pb}$ & Co & $\mathrm{Pb}$ \\
\hline \multicolumn{2}{|l|}{ SRM 1643e } & $27.06 \pm 0.3$ & $19.63 \pm 0.2$ & $26.8 \pm 0.82$ & $19.24 \pm 0.5$ & $99.0 \%(3.06 \%)$ & $98.0 \%(2.60 \%)$ \\
\hline \multicolumn{8}{|c|}{ (b) } \\
\hline \multirow{2}{*}{ Samples } & \multicolumn{2}{|c|}{ Added $\left(\mu \mathrm{g} \mathrm{L}^{-1}\right)$} & \multicolumn{3}{|c|}{ Measured $\left(\mu \mathrm{g} \mathrm{L}^{-1}\right)$} & \multicolumn{2}{|c|}{ Recovery (\%) } \\
\hline & Co & $\mathrm{Pb}$ & & Co & $\mathrm{Pb}$ & Co & $\mathrm{Pb}$ \\
\hline \multirow{4}{*}{ Canal water } & 0 & 0 & & $3.34 \pm 0.962$ & $6.08 \pm 0.781$ & - & - \\
\hline & 2 & 2 & & $5.32 \pm 0.384$ & $8.06 \pm 0.822$ & 99.8 & 99 \\
\hline & 5 & 5 & & $8.33 \pm 0.432$ & $11.0 \pm 0.784$ & 100 & 98.4 \\
\hline & 10 & 10 & & $13.3 \pm 0.642$ & $15.9 \pm 0.828$ & 99.6 & 98.2 \\
\hline
\end{tabular}

Mean $\pm \operatorname{SD}(n=3)$.

TABLE 4: Determination of lead and cobalt in water samples.

\begin{tabular}{lcc}
\hline Sample & $\operatorname{Co}\left(\mu \mathrm{g} \mathrm{L}^{-1}\right)$ & $\mathrm{Pb}\left(\mu \mathrm{g} \mathrm{L}^{-1}\right)$ \\
\hline Canal water & $3.34 \pm 0.962$ & $6.08 \pm 0.781$ \\
Waste water & $14.6 \pm 1.20$ & $17.3 \pm 1.52$ \\
\hline
\end{tabular}

Mean \pm SD $(n=3)$.

ratio is an important factor, which has an effect on the extraction recovery of cations. A low phases ratio improves the recovery of analytes, but decreases the preconcentration factor. However, to determine the optimum amount of the phase ratio, different volumes of a water sample 10-1000 mL and a constant volume of surfactant solution $0.5 \%$ were chosen. The obtained results show that with increasing the sample volume $>100 \mathrm{~mL}$, the extracted understudy analytes were decreased as compared to those obtained with 25$50 \mathrm{~mL}$. A successful cloud point extraction should maximize the extraction efficiency by minimizing the phase volume ratio, thus improving its concentration factor. In the present work, the initial sample volume was $25 \mathrm{~mL}$ and the final volume of surfactant rich phase after diluted with acidic ethanol was $0.5 \mathrm{~mL}$, hence the PCF achieved in this work was 50 for both understudy analytes. 
TABle 5: Comparative table for determination of cobalt and lead in different types of samples applying CPE before analysis by atomic spectrometric technique.

\begin{tabular}{|c|c|c|c|c|}
\hline Reagent and surfactant & Matrix and technique & $\mathrm{PF}^{\mathrm{a}}$ and $\mathrm{EF}^{\mathrm{b}}$ & $\operatorname{LOD}^{\mathrm{c}}\left(\mu \mathrm{g} \mathrm{L}^{-1}\right)$ & Reference \\
\hline \multicolumn{5}{|c|}{ Cobalt } \\
\hline TAN/Triton X-114 & Water/(FAAS) & $-157^{b}$ & 0.24 & {$[25]$} \\
\hline PAN/TX-100 & Water samples/(GFAAS) & $-/ 100^{\mathrm{b}}$ & 0.003 & {$[31]$} \\
\hline PAN/TX-114 & Urine/(FAAS) & $-/ 115^{\mathrm{b}}$ & 0.38 & {$[32]$} \\
\hline 5-Br-PADAP/TX-100-SDS & Pharmaceutical samples/(FAAS) & $-/ 29^{b}$ & 1.1 & {$[14]$} \\
\hline TAN/Triton X-100 & Water/(GFAAS) & $-/ 100^{\mathrm{b}}$ & 0.003 & {$[33]$} \\
\hline APDC/Triton X-114 & Biological tissues/(TS-FF-FAAS) & $-/ 130^{\mathrm{b}}$ & 2.1 & {$[34]$} \\
\hline APDC/Triton X-114 & Water/(FAAS) & $-/ 20^{\mathrm{b}}$ & 5.0 & {$[23]$} \\
\hline 1,2-N,N /PONPE 7.5 & Water sample/(FAAS) & $-/ 27^{\mathrm{b}}$ & 1.22 & [35] \\
\hline Me-BTABr/Triton X-114 & Water sample/(FAAS) & $-/ 28^{\mathrm{b}}$ & 0.9 & {$[36]$} \\
\hline Oxine/Triton X-114 & Water sample/(FAAS) & $50 / 50$ & 0.44 & Present work \\
\hline \multicolumn{5}{|c|}{ Lead } \\
\hline 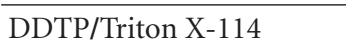 & Human hair/(FAAS) & $-/ 43^{b}$ & 2.86 & {$[28]$} \\
\hline PONPE 7.5/- & Human saliva/(FAAS) & $-/ 10^{\mathrm{b}}$ & - & [37] \\
\hline APDC/Triton X-114 & Certified biological reference materials/(ETAAS) & $-/ 22.5^{b}$ & $0.04^{\mathrm{c}} /-$ & {$[24]$} \\
\hline DDTP/Triton X-114 & Certified blood reference samples/(ETAAS) & $-134^{\mathrm{b}}$ & 0.08 & {$[38]$} \\
\hline PONPE $7.5 /-$ & Tap water certified reference material/(ICP-OES) & $-/>300^{\mathrm{b}}$ & 0.07 & {$[39]$} \\
\hline DDTP/Triton X-114 & Riverine and sea water enriched water reference materials/(ICP-MS) & $-1-$ & 40.0 & {$[40]$} \\
\hline 5-Br-PADAP/Triton X-114 & Water/(GFAAS) & $50^{\mathrm{a}} /-$ & $0.08^{c} /-$ & {$[41]$} \\
\hline PAN/Triton X-114 & Water/(FAAS) & $-/ 55.6^{\mathrm{b}}$ & 1.1 & [27] \\
\hline -/Tween 80 & Environmental sample/FAAS & $10^{\mathrm{a}} /-$ & 7.2 & {$[42]$} \\
\hline TAN/Triton X-114 & Water sample/(FAAS) & $15.1^{\mathrm{a}} /$ - & 4.5 & {$[43]$} \\
\hline Pyrogallol/Triton X-114 & Water sample/(FAAS) & $72^{\mathrm{a}} /-$ & 0.4 & {$[44]$} \\
\hline Oxine/Triton X-114 & Water sample/(FAAS) & $50 / 70$ & 0.26 & Present work \\
\hline
\end{tabular}

a preconcentration factor, ${ }^{b}$ enhancement factor, and climit of detection.

3.6. Interferences. The interference is those relating to the preconcentration step, which may react with oxine and decrease the extraction. To perform this study, $25 \mathrm{~mL}$ solution containing $20 \mu \mathrm{g} / \mathrm{L}^{-1}$ of both metals at different interference to analyte ratio were subjected to the developed procedure. Table 1 shows the tolerance limits of the interfering ions error $<5 \%$. The tolerance limit of coexisting ions is defined as the largest amount making variation of less than $5 \%$ in the recovery of analytes. The effects of representative potential interfering species were tested. Commonly encountered matrix components such as alkali and alkaline earth elements generally do not form stable complexes under the experimental conditions. A high concentration of oxine reagent was used, for the complete chelation of the selected ions even in the presence of interferent ions.

3.7. Analytical Figures of Merit. The calibration graph using the preconcentration step for $\mathrm{Co}$ and $\mathrm{Pb}$ were linear with a concentration range of $5.0-20 \mathrm{ug} \mathrm{L}^{-1}$ of standards and subjecting to $\mathrm{CPE}$ methods at optimum levels of all understudy variables. The extracted analytes in diluted micellar media were introduced into the flame by conventional aspiration. Table 2 gives the calibration parameters for the proposed CPE method including the linear ranges, relative standard deviation RSD, and limit of detection LOD. The experimental enhancement factors calculated as the ratio of the slopes of calibration graphs with and without preconcentration. The enhancement factors of $\mathrm{Co}$ and $\mathrm{Pb}$ subjected to $\mathrm{CPE}$ method were found to be 70 and 50 , respectively. The limits of detection LOD were calculated as the ratio between three times the standard deviation of ten blank readings and the slope of the calibration curve after preconcentration were calculated as 0.26 and $0.44 \mu \mathrm{g} \mathrm{L}^{-1}$, respectively, for $\mathrm{Co}$ and $\mathrm{Pb}$. The obtained LOD was sufficiently low for detecting trace levels of $\mathrm{Co}$ and $\mathrm{Pb}$ in different types of fresh and waste water samples.

The accuracy of the proposed method was evaluated by analyzing a standard reference material of water SRM-1643e with certified values of $\mathrm{Co}$ and $\mathrm{Pb}$ content. It was found that there is no significant difference between results obtained by the proposed method and the certified results of both metals. Reliability of the proposed method was also checked by spiking both metals at to three concentration levels $(2.0-$ $\left.10.0 \mu \mathrm{g} \mathrm{L}^{-1}\right)$ in a real water sample. The results are presented in Tables 3(a) and 3(b). The perecentage of recoveries $(R)$ of spike standards were calculated as follows:

$$
R(\%)=\frac{\left(C_{m}-C_{\mathrm{o}}\right)}{m} \times 100,
$$

where $C_{m}$ is a value of metal in a spiked sample, $C_{0}$ the value of metal in a sample, and $m$ is the amount of metal spiked. 
These results demonstrate the applicability of developed procedure for $\mathrm{Co}$ and $\mathrm{Pb}$ determination in different water samples.

3.8. Application to Real Samples. The CPE procedure was applied to determine $\mathrm{Co}$ and $\mathrm{Pb}$ in fresh surface and waste water samples. The results are shown in Table 4. The Co and $\mathrm{Pb}$ concentrations in fresh surface water were found in the range of $2.12-5.12 \mu \mathrm{g} \mathrm{L}^{-1}$ and $1.49-8.56 \mu \mathrm{g} \mathrm{L}^{-1}$, respectively. In waste water, the levels of both analyte were high, found in the range of $13.6-16.8$ and $15.1-19.4 \mu \mathrm{g} \mathrm{L}^{-1}$ for $\mathrm{Co}$ and $\mathrm{Pb}$, respectively.

\section{Conclusion}

In this study, Triton X-114 was chosen for the formation of the surfactant-rich phase due to its excellent physicochemical characteristics, low cloud point temperature, high density of the surfactant-rich phase, which facilitates phase separation easily by centrifugation, and commercial availability and relatively low price and low toxicity. This method is a promising alternative for the determination of Co and $\mathrm{Pb}$ linked with FAAS. From the results obtained, it can be considered that oxine is an efficient ligand for cloud point extraction of $\mathrm{Co}$ and $\mathrm{Pb}$. The simple accessibility, the formation of stable complexes, and consistency with the cloud point extraction method are the major advantages of the use of oxine in cloud point extraction of Co and $\mathrm{Pb}$. CPE has been shown to be a practicable and versatile method, being adequate for environmental studies. Cloud point extraction is an easy, safe, rapid, inexpensive, and environmentally friendly methodology for preconcentration and separation of trace metals in aqueous solutions. The surfactant-rich phase can be directly introduced into flame atomic absorption spectrometer FAAS after dilution with acidic ethanol. The proposed CPE method incorporating oxine as chelating agent permits effective separation and preconcentration of $\mathrm{Co}$ and $\mathrm{Pb}$ and final determination by FAAS provides a novel route for trace determination of these metals in water samples of different ecosystem. A low-cost surfactant was used, thus toxic organic solvent extraction generating waste disposal problems was avoided. The comparison of the results found in the presented study and some works in the literature was given in [31-44]. The proposed cloud point extraction method is superior for having lower detection limits when compared to other methods as shown in Table 5 .

\section{Acknowledgment}

The authors would like to thank the National center of Excellence in Analytical Chemistry (NCEAC), University of Sindh, Jamshoro, for providing financial support and excellent research lab facilities for scholars to carry out the research work.

\section{References}

[1] M. Soylak, L. Elci, and M. Dogan, "Determination of some trace metals in dial- ysis solutions by atomic absorption spectrometry after preconcentration," Analytical Letters, vol. 26, pp. 1997-2007, 1993.

[2] Y. Bayrak, Y. Yesiloglu, and U. Gecgel, "Adsorption behavior of $\mathrm{Cr}(\mathrm{VI})$ on activated hazelnut shell ash and activated bentonite," Microporous and Mesoporous Materials, vol. 91, no. 1-3, pp. 107-110, 2006.

[3] M. Kobya, E. Demirbas, E. Senturk, and M. Ince, "Adsorption of heavy metal ions from aqueous solutions by activated carbon prepared from apricot stone," Bioresource Technology, vol. 96, no. 13, pp. 1518-1521, 2005.

[4] M. Kazemipour, M. Ansari, S. Tajrobehkar, M. Majdzadeh, and H. R. Kermani, "Removal of lead, cadmium, zinc, and copper from industrial wastewater by carbon developed from walnut, hazelnut, almond, pistachio shell, and apricot stone," Journal of Hazardous Materials, vol. 150, no. 2, pp. 322-327, 2008.

[5] F. Shah, T. G. Kazi, H. I. Afridi et al., "Environmental exposure of lead and iron deficit anemia in children age ranged 1-5years: a cross sectional study," Science of the Total Environment, vol. 408, no. 22, pp. 5325-5330, 2010.

[6] D. L. Tsalev and Z. K. Zaprianov, Atomic Absorption in Occupational and Environmental Health Practice, Analytical Aspects and Health Significance, CRC Press, Boca Raton, Fla, USA, 1983.

[7] H. G. Seiler, A. Siegel, and H. Siegel, Handbook on Metals in Clinical and Analytical Chemistry, Marcel Dekker, New York, NY, USA, 1994.

[8] A. Sasmaz and M. Yaman, "Distribution of chromium, nickel, and cobalt in different parts of plant species and soil in mining area of Keban, Turkey," Communications in Soil Science and Plant Analysis, vol. 37, pp. 1845-1857, 2006.

[9] M. Soylak, L. Elci, and M. Dogan, "Determination of trace amounts of cobalt in natural water samples as 4-(2Thiazolylazo) recorcinol complex after adsorptive preconcentration," Analytical Letters, vol. 30, no. 3, pp. 623-631, 1997.

[10] M. Soylak, L. Elci, I. Narin, and M. Dogan, "Application of solid phase extraction for the preconcentration and separation of trace amounts of cobalt from urin," Trace Elements and Electrolytes, vol. 18, pp. 26-29, 2001.

[11] V. A. Lemos and G. T. David, "An on-line cloud point extraction system for flame atomic absorption spectrometric determination of trace manganese in food samples," Microchemical Journal, vol. 94, no. 1, pp. 42-47, 2010.

[12] M. Ghaedi, M. R. Fathi, F. Marahel, and F. Ahmadi, "Simultaneous preconcentration and determination of copper, nickel, cobalt and lead ions content by flame atomic absorption spectrometry," Fresenius Environmental Bulletin, vol. 14, no. 12 B, pp. 1158-1163, 2005.

[13] M. D. G. Pereira and M. A. Z. Arruda, "Trends in preconcentration procedures for metal determination using atomic spectrometry techniques," Mikrochimica Acta, vol. 141, no. 34, pp. 115-131, 2003.

[14] C. C. Nascentes and M. A. Z. Arruda, "Cloud point formation based on mixed micelles in the presence of electrolytes for cobalt extraction and preconcentration," Talanta, vol. 61, no. 6, pp. 759-768, 2003.

[15] A. Shokrollahi, M. Ghaedi, S. Gharaghani, M. R. Fathi, and M. Soylak, "Cloud point extraction for the determination of copper in environmental samples by flame atomic absorption spectrometry," Quimica Nova, vol. 31, no. 1, pp. 70-74, 2008. 
[16] J. A. Baig, T. G. Kazi, A. Q. Shah et al., "Optimization of cloud point extraction and solid phase extraction methods for speciation of arsenic in natural water using multivariate technique," Analytica Chimica Acta, vol. 651, no. 1, pp. 57-63, 2009.

[17] P. Liu, Q. Pu, and Z. Su, "Synthesis of silica gel immobilized thiourea and its application to the on-line preconcentration and separation of silver, gold and palladium," Analyst, vol. 125, no. 1 , pp. $147-150,2000$.

[18] C. D. Stalikas, "Micelle-mediated extraction as a tool for separation and preconcentration in metal analysis," $\operatorname{Tr} A C$ Trends in Analytical Chemistry, vol. 21, no. 5, pp. 343-355, 2002.

[19] Z. Wang, M. Jing, F. S. Lee, and X. Wang, "Synthesis of 8hydroxyquinoline Bonded Silica (SHQ) and its application in flow injection-inductively coupled plasma mass spectrometry analysis of trace metals in seawater," Chinese Journal of Analytical Chemistry, vol. 34, no. 4, pp. 459-462, 2006.

[20] X.-J. Sun, B. Welz, and M. Sperling, "Determination of lead in wine by the FIAS-FAAS combination on-line preconcentration system," Chemical Journal of Chinese Universities, vol. 17, no. 8, pp. 1219-1221, 1996.

[21] M. Soylak, "Determination of trace amounts of copper in high-purity aluminum samples after preconcentration on an activated carbon column," Fresenius Environmental Bulletin, vol. 7, no. 7-8, pp. 383-387, 1998.

[22] J. L. Manzoori and G. Karim-Nezhad, "Development of a cloud point extraction and preconcentration method for $\mathrm{Cd}$ and $\mathrm{Ni}$ prior to flame atomic absorption spectrometric determination," Analytica Chimica Acta, vol. 521, no. 2, pp. 173-177, 2004.

[23] D. L. Giokas, E. K. Paleologos, S. M. Tzouwara-Karayanni, and M. I. Karayannis, "Single-sample cloud point determination of iron, cobalt and nickel by flow injection analysis flame atomic absorption spectrometry-application to real samples and certified reference materials," Journal of Analytical Atomic Spectrometry, vol. 16, no. 5, pp. 521-526, 2001.

[24] J. L. Manzoori and A. Bavili-Tabrizi, "The application of cloud point preconcentration for the determination of $\mathrm{Cu}$ in real samples by flame atomic absorption spectrometry," Microchemical Journal, vol. 72, no. 1, pp. 1-7, 2002.

[25] J. Chen and K. C. Teo, "Determination of cobalt and nickel in water samples by flame atomic absorption spectrometry after cloud point extraction," Analytica Chimica Acta, vol. 434, no. 2, pp. 325-330, 2001.

[26] J. L. Manzoori and A. Bavili-Tabrizi, "Cloud point preconcentration and flame atomic absorption spectrometric determination of cobalt and nickel in water samples," Mikrochimica Acta, vol. 141, no. 3-4, pp. 201-207, 2003.

[27] J. Chen and K. C. Teo, "Determination of cadmium, copper, lead and zinc in water samples by flame atomic absorption spectrometry after cloud point extraction," Analytica Chimica Acta, vol. 450, no. 1-2, pp. 215-222, 2001.

[28] J. L. Manzoori and A. Bavili-Tabrizi, "Cloud point preconcentration and flame atomic absorption spectrometric determination of $\mathrm{Cd}$ and $\mathrm{Pb}$ in human hair," Analytica Chimica Acta, vol. 470, no. 2, pp. 215-221, 2002.

[29] A. Ohashi, H. Ito, C. Kanai, H. Imura, and K. Ohashi, "Cloud point extraction of iron(III) and vanadium(V) using 8-quinolinol derivatives and Triton X-100 and determination of 10-7 mol dm -3 level iron(III) in riverine water reference by a graphite furnace atomic absorption spectroscopy," Talanta, vol. 65 , no. 2 , pp. 525-530, 2005 .
[30] D. Zhao, R. Bian, Y. Ding, and L. Li, "Determination of lead and cadmium in water samples by cloud point extraction prior to flame atomic absorption spectrometry determination," Journal of the Iranian Chemical Research, vol. 6, no. 2, pp. 8794, 2009.

[31] Y. Zhang, W. H. Luo, and H. Li, "Determination of trace cobalt in water samples by gra phite furnace a tomic absorption spectrometry after cloud point," Spectroscopy Spectral Analysis, vol. 25, pp. 576-578, 2005.

[32] J. L. Manzoori and G. Karim-Nezhad, "Sensitive and simple cloud-point preconcentration atomic absorption spectrometry: application to the determination of cobalt in urine samples," Analytical Sciences, vol. 19, no. 4, pp. 579-583, 2003.

[33] Ma. C. C. Oliveros, O. J. De Blas, J. L. P. Pavón, and B. M. Cordero, "Cloud point preconcentration and flame atomic absorption spectrometry: application to the determination of nickel and zinc," Journal of Analytical Atomic Spectrometry, vol. 13, no. 6, pp. 547-550, 1998.

[34] G. L. Donati, C. C. Nascentes, A. R. A. Nogueira, M. A. Z. Arruda, and J. A. Nóbrega, "Acid extraction and cloud point preconcentration as sample preparation strategies for cobalt determination in biological materials by thermospray flame furnace atomic absorption spectrometry," Microchemical Journal, vol. 82, no. 2, pp. 189-195, 2006.

[35] J. L. Manzoori and A. Bavili-Tabrizi, "Cloud point preconcentration and flame atomic absorption spectrometric determination of cobalt and nickel in water samples," Mikrochimica Acta, vol. 141, no. 3-4, pp. 201-207, 2003.

[36] V. A. Lemos, R. d. França, and B. O. Moreira, "Cloud point extraction for $\mathrm{Co}$ and $\mathrm{Ni}$ determination in water samples by flame atomic absorption spectrometry," Separation and Purification Technology, vol. 54, no. 3, pp. 349-354, 2007.

[37] M. O. Luconi, M. F. Silva, R. A. Olsina, and L. P. Fernández, "Cloud point extraction of lead in saliva via use of nonionic PONPE 7.5 without added chelating agents," Talanta, vol. 51, no. 1, pp. 123-129, 2000.

[38] F. Shemirani, M. Baghdadi, M. Ramezani, and M. R. Jamali, "Determination of ultra trace amounts of bismuth in biological and water samples by electrothermal atomic absorption spectrometry (ET-AAS) after cloud point extraction," Analytica Chimica Acta, vol. 534, no. 1, pp. 163-169, 2005.

[39] M. O. Luconi, L. L. Sombra, M. F. Silva, L. D. Martinez, R. O. Olsina, and L. P. Fernandez, "Determination of lead by flow injection-inductively coupled plasma.optical emission spectrometry after cloud point enrichment without chelating agents," Chemia Analityczna, vol. 48, p. 749, 2003.

[40] M. A. M. Da Silva, V. L. A. Frescura, and A. J. Curtius, "Determination of trace elements in water samples by ultrasonic nebulization inductively coupled plasma mass spectrometry after cloud point extraction," Spectrochimica acta, Part B, vol. 55, no. 7, pp. 803-813, 2000.

[41] J. Chen, S. Xiao, X. Wu, K. Fang, and W. Liu, "Determination of lead in water samples by graphite furnace atomic absorption spectrometry after cloud point extraction," Talanta, vol. 67, no. 5, pp. 992-996, 2005.

[42] S. Candir, I. Narin, and M. Soylak, "Ligandless cloud point extraction of $\mathrm{Cr}(\mathrm{III}), \mathrm{Pb}(\mathrm{II}), \mathrm{Cu}(\mathrm{II}), \mathrm{Ni}(\mathrm{II}), \mathrm{Bi}(\mathrm{III})$, and $\mathrm{Cd}(\mathrm{II})$ ions in environmental samples with Tween 80 and flame atomic absorption spectrometric determination," Talanta, vol. 77, no. 1, pp. 289-293, 2008.

[43] H. Sang, P. Liang, and D. Du, "Determination of trace aluminum in biological and water samples by cloud point extraction preconcentration and graphite furnace atomic 
absorption spectrometry detection," Journal of Hazardous Materials, vol. 154, no. 1-3, pp. 1127-1132, 2008.

[44] F. Shemirani, S. D. Abkenar, and A. Khatouni, "Determination of trace amounts of lead and copper in water samples by flame atomic absorption spectrometry after cloud point extraction," Bulletin of the Korean Chemical Society, vol. 25, no. 8, pp. 11331136, 2004. 


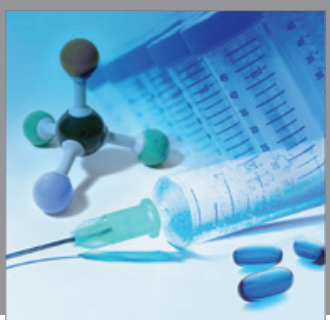

International Journal of

Medicinal Chemistry

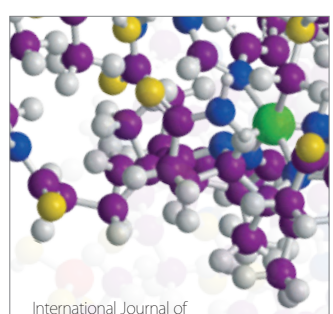

Carbohydrate Chemistry

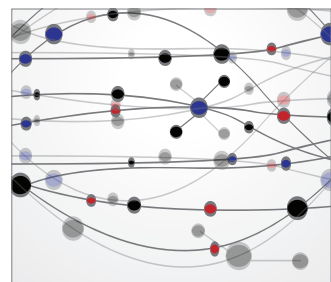

The Scientific World Journal
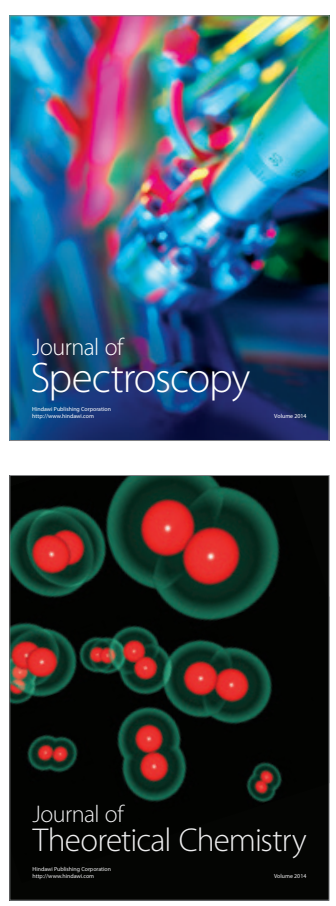
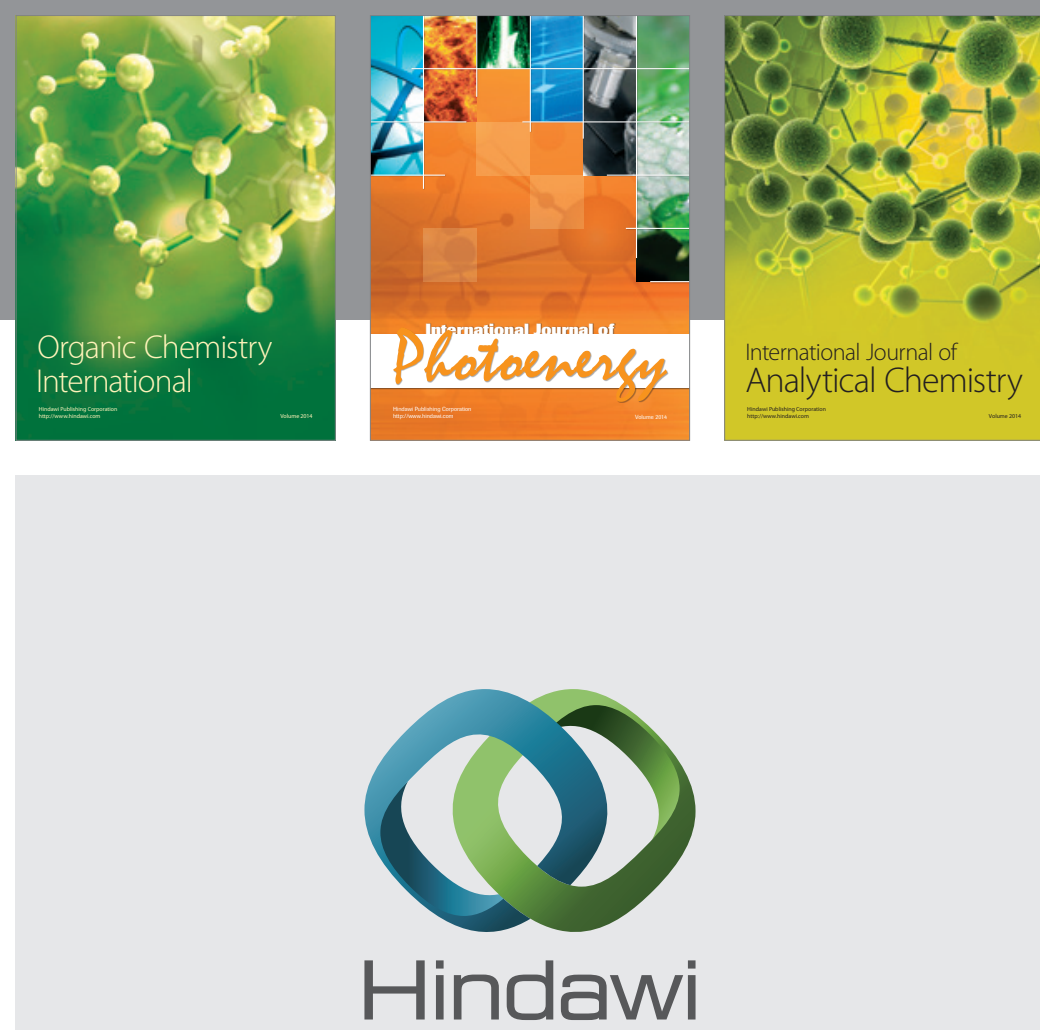

Submit your manuscripts at

http://www.hindawi.com
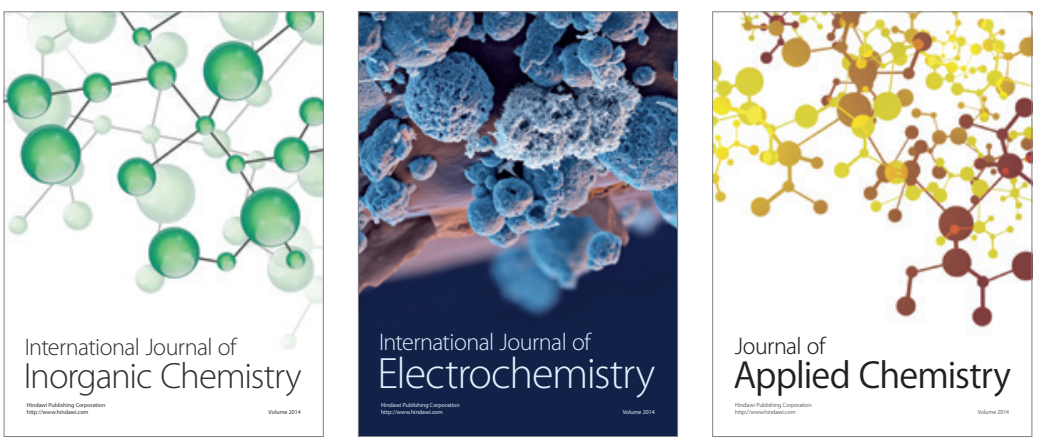

Journal of

Applied Chemistry
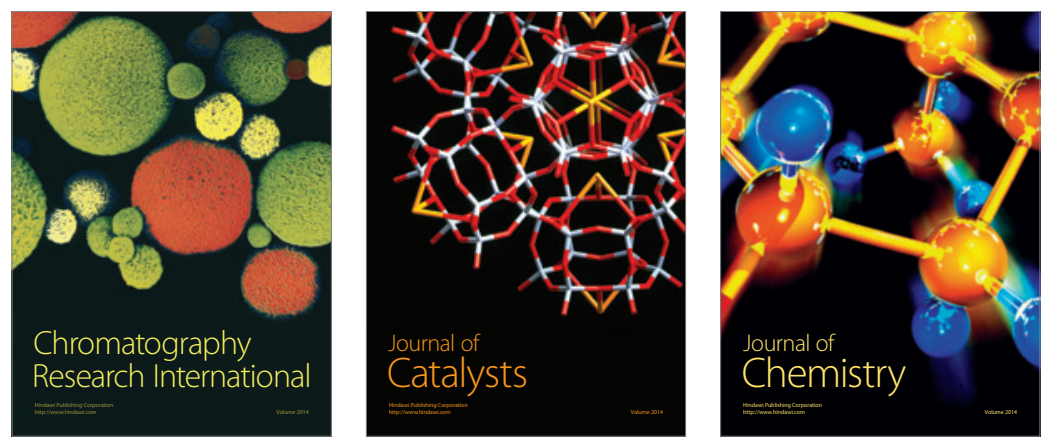
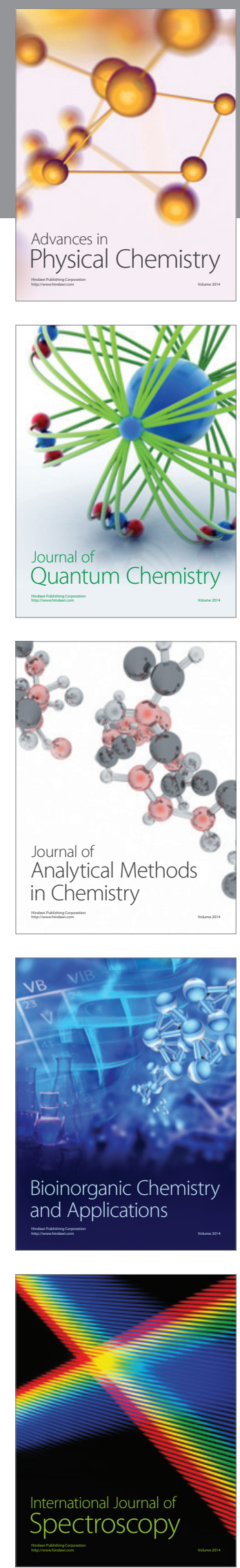